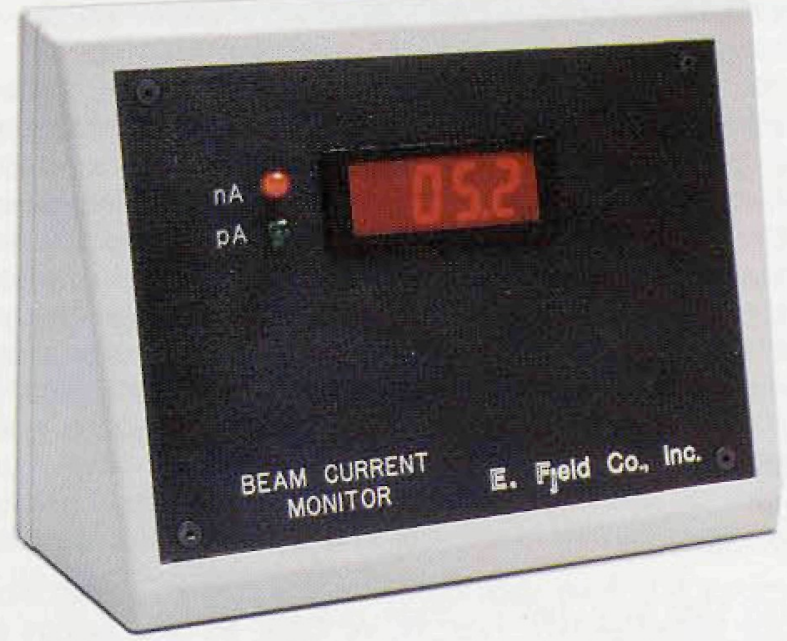

\section{DIAMOND KNIVES}

EdgeCraft Corporation has announced the availability of Wet \& Dy Cyo, Histo \& Material Science Type 2 diamond knife versions fo their EdgeCraft ${ }^{6}$ Diamond Knife ${ }^{T M}$ used for the preparation of sections for both electron \& light microscopy. These products are in addition to their Standard Ultrathin EdgeCraft Diamond Knife \|\|$^{T M}$ introduced several months ago. In addition EdgeCraft has introduced a NEW World Wide Web site which can be accessed at http://www.edgecraft.com

EdgeCraft Corporation

$(800) 343-3255$ or $(610) 268-0500$ - Fax: $(610) 268-3545$ eMail: info@edgecraft or diamondpa@aol.com Circle Reader Inquiry \#41

\section{BEAM CURRENT MONITOR}

E. Field Co., Inc. introduces a fast, effective method to monitor and maintain delivered beam current for specific scientific analysis. A self-contained, autoranging Beam Current Monitor allows the operator to monitor single-digit picoamps or hundreds of nanoamps. The easy-to-read LCD device installs quickly and consumes only $3 \times 7$ inches of operational space.

In addition, the Beam Current Monitor has been designed for ease of operation. Simply direct the electron beam into a Faraday Cup and power the Beam Current Monitor. The display will automatically illuminate the 3-digit LCD display. Autoranging begins immediately, precisely adjusting to the existing input current levels. The input range is 0 to $-200 \mathrm{nA}$

Ideal for EDSWDS analysis or any operation requiring control and/or repetition of delivered beam current. Faraday attachments and elemental standards are available to complete the Beam Current Monitor package. PRICED@ $\$ 985.00$

E. Fjeld Co., Inc., 3 Executive Park Drive, N. Billerica, MA 01862 (508)667-1416 - Fax: (508)667-9059 Circle Reader Inquiry \#40

\section{Oxford Instruments Launches Link ${ }^{\mathrm{TM}}$ OPALMAPTM}

$L_{\text {ink }}{ }^{\text {TM }}$ OpalMap ${ }^{\mathrm{TM}}$ drives the microscope electron beam over the sample to collect an electron backscattering pattern (EBSP) at each grid of points. Using advanced image processing techniques, the EBSP is solved to calculate the crystal orientation at each point. From this data, maps of the crystal orientation can be displayed and the microstructure of the sample regenerated. Capabilities of $L_{i n k^{T M}}$ OpalMap ${ }^{T M}$ go beyond an elementary combination of mapping and electron backscattered diffraction. Comprehensive software is supplied for grain boundary characterization and for studying the relationship between microtexture and grain orientations.

Oxford Instruments, Microanalysis Group: (508)369-9933, Fax: (508)369-8287 Circle Reader Inquiry $\$ 42$

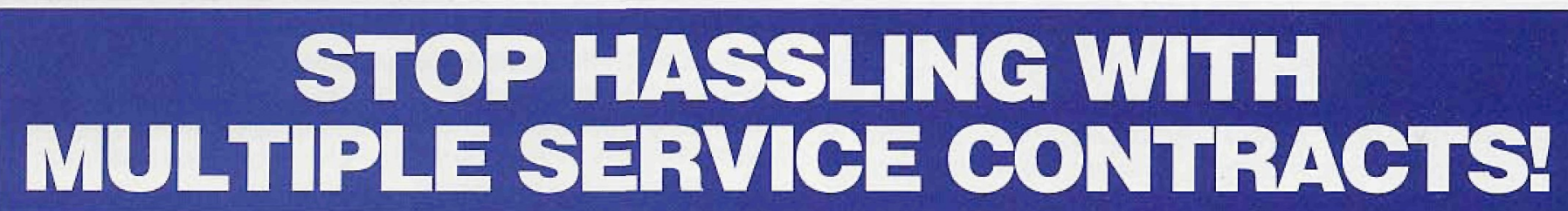

START by putting all of your instruments under one contract with MAS

(regardless of make or model). Our expert EM SERVICE GROUP has the knowledge and skill to keep your instrumentation working at its best.

\section{TEM'S/ SEM'S \\ HITACHI \\ JEOL \\ AMRAY \\ CAMBRIDGE \\ TOPCON

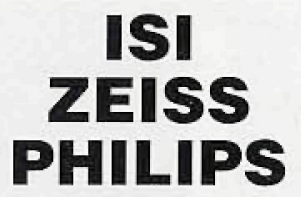

We service all brands under one contract.
PREP EQUIPMENT ULTRAMICROTOMES
DUPONT \& RMC

VACUUM COATERS

SPUTTER COATERS

MECHANICAL PUMPS

TURBO PUMPS

PLASMA ASHERS
WE SERVICE

COMPUTER CONTROLLERS

BEAM BLANKERS

WATER CHILLERS
Contracts and On-Demand

Emergency Service at

Reasonable Rates from

Factory Trained Specialists.

1-800-421-8451
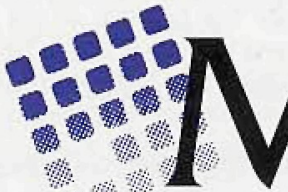

MATERIALS ANALYTICAL SERVICES
3597 Parkway Lane • Suite 250 • Norcross, Georgia 30092 • 770-448-3200 • FAX 770-368-8256 or 616 Hutton Street • Suite 101 • Raleigh, North Carolina 27606 • 919-829-7041 • FAX919-829-5518 ADVANCED ANALYTICAL PRODUCTS AND SERVICES 